\title{
Groundwater level changes related to the ground shaking of the Noto Hanto Earthquake in 2007
}

\author{
Satoshi Itaba ${ }^{1}$, Naoji Koizumi ${ }^{1}$, Norio Matsumoto ${ }^{1}$, Makoto Takahashi ${ }^{1}$, Tsutomu Sato ${ }^{1}$, Ryu Ohtani ${ }^{1}$, \\ Yuichi Kitagawa ${ }^{1}$, Yasuto Kuwahara ${ }^{1}$, Takashi Sato ${ }^{1}$, and Kunio Ozawa ${ }^{2}$ \\ ${ }^{1}$ Geological Survey of Japan, National Institute of Advanced Industrial Science and Technology (AIST), \\ 1-1-1 Higashi, Tsukuba, Ibaraki, Japan \\ ${ }^{2}$ Disaster Prevention Bureau, Shizuoka Prefectural Government, Japan
}

(Received July 9, 2007; Revised December 4, 2007; Accepted December 5, 2007; Online published December 10, 2008)

\begin{abstract}
The Geological Survey of Japan, AIST has been monitoring groundwater using the observation network of about 40 stations in and around the Kinki and Tokai districts for earthquake prediction research. The Noto Hanto Earthquake in 2007 ( $M_{\text {JMA }}$ 6.9) occurred in the northwestern part of the Noto Hanto Peninsula, Japan on March 25, 2007. The epicentral distance to the nearest and furthest observation well is about $100 \mathrm{~km}$ and $400 \mathrm{~km}$, respectively. Changes in groundwater level related to the Noto Hanto Earthquake were detected at many stations. Most of these were changes in the long-term trend and/or short-term oscillation; there were a few steplike changes. The coseismic static volumetric strain changes calculated from the fault model ranged between $10^{-9}$ and $10^{-10}$ at most of the observation stations. These changes were therefore considered to be groundwater changes caused by the ground shaking because groundwater level sensitivity to crustal volumetric strain is a few centimeters to $10^{-8}$ strain at the most. We compared the coseismic groundwater level changes for the Noto Hanto Earthquake with those for five recent large earthquakes and obtained rough characteristics of the effect of the ground shaking on the groundwater level at each of the observation stations.
\end{abstract}

Key words: Groundwater level, strain, coseismic change, oscillation, Noto Hanto Earthquake in 2007.

\section{Introduction}

Earthquake-related groundwater level changes have been reported repeatedly (Wakita, 1975; Roeloffs, 1988, 1996; Koizumi et al., 1996). Quantitative evaluations of the relationship between the groundwater level and crustal static strain changes associated with earthquakes have been performed in recent years (Igarashi and Wakita, 1991; Quilty and Roeloffs, 1997; Koizumi et al., 2004). Akita and Matsumoto (2004) investigated coseismic groundwater level changes in a great many observation wells in Hokkaido, Japan induced by five earthquakes with $M>7.5$ that occurred around the Hokkaido region. These researchers showed that groundwater level changes could generally be explained by coseismic static volumetric strain changes. However, coseismic static strain changes have not been able to explain earthquake-related groundwater level changes on all occasions (Rojstaczer et al., 1995; Koizumi et al., 1996; Lai et al., 2004).

As was reported by Montgomery and Manga (2003), ground shaking, which involves dynamic strain changes, in addition to coseismic strain changes, is also a causal main factor of earthquake-related groundwater level changes. Ground shaking causes consolidation, fracturing, fracture clearing or permeability enhancement (Brodsky et al., 2003) and liquefaction, all of which subsequently induce

Copyright (c) The Society of Geomagnetism and Earth, Planetary and Space Sciences (SGEPSS); The Seismological Society of Japan; The Volcanological Society of Japan; The Geodetic Society of Japan; The Japanese Society for Planetary Sciences; TERRAPUB. groundwater level changes. Therefore, the effect of ground shaking is considered to greatly depend on geological structures as well as on the amplitudes and frequencies of the ground shaking (Lai et al., 2004). Coseismic static strain changes generally attenuate in proportion to the cube of the hypocentral distance. In contrast, amplitudes of ground shaking attenuate in proportion to the hypocentral distance in the case of a body wave or to the route of the epicentral distance in the case of a surface wave. Therefore, as the hypocentral or epicentral distance is larger, the effect of ground shaking on groundwater level changes becomes larger than that of coseismic static strain changes. In actual fact, the sensitivity of groundwater level to crustal volumetric strain is a few centimeters to $10^{-8}$ strain at most (Roeloffs, 1996; Kitagawa et al., 2004). It is therefore important to evaluate the effect of ground shaking on the groundwater level in the area where there are some coseismic and/or postseismic groundwater level changes but also where estimated coseismic static strain changes are smaller than $10^{-8}$. A reasonable estimate of the effect of ground shaking can provide useful information for long-term evaluation of the stability of groundwater in the area.

The Noto Hanto Earthquake in 2007 occurred at the northwestern part of the Noto Hanto, Japan on March 25, 2007. This earthquake has an $M_{\mathrm{JMA}}=6.9$, and the epicentral distances to almost all of our observation stations are $200-300 \mathrm{~km}$. The coseismic static volumetric strain changes expected by the fault model of the earthquake (Awata et al., 2007) is very small or ranges between $10^{-9}$ 
and $10^{-10}$ at most of our groundwater observation stations. In contrast, the seismic intensity of each station was two to three on the scale of the Japan Meteorological Agency. Since the sensitivity of the groundwater level to volumetric strain change is a few centimeters to $10^{-8}$ strain at most, groundwater level changes caused by these small volumetric strain changes are expected to be $1 \mathrm{~mm}$ or smaller at most of the observation stations. Therefore it seems important to consider the effects of ground shaking in this case.

Here, we show groundwater changes related to the Noto Hanto Earthquake in 2007 and evaluate the effects of ground shaking on the groundwater level. We will compare the results with those of the other recent large earthquakes and try to determine the characteristics of the effects. In the following discussion, "coseismic strain changes" means "coseismic static strain changes".

\section{Observation and Method}

The Geological Survey of Japan (GSJ), AIST, has been monitoring groundwater as a means for predicting earthquakes since 1976. The groundwater observation network of GSJ currently comprises 42 stations in and around the Tokai and Kinki areas. At each station, groundwater level in an open well or pressure in a sealed well is observed as pore water pressure in the aquifer. For convenience, in this paper, the data on the groundwater pressure are expressed in the same units as those of the groundwater level. The data at 37 of the 42 stations, where the instruments for the observation worked well before and after the Noto Hanto Earthquake, were used for this analysis. The positions of those 37 observation stations are shown in Fig. 1. The sampling interval of the observed data is $2 \mathrm{~min}$ at most of the stations or $10 \mathrm{~min}$ at the other stations. Some of the observation stations have more than one observation well. We judged that the coseismic groundwater level change occurred at such observation stations if one of the wells was subjected to the coseismic change.

The sensitivity of the groundwater level to crustal volumetric strain is presumed by the tidal response of the groundwater level. Tidal components were extracted from the groundwater level data for 3 months before the Noto Hanto Earthquake using the BAYTAP-G program (Tamura et al., 1991). The amplitude of the tidal volumetric strain at each observation station, which includes the components of the earth and oceanic tides, was calculated using the GOTIC2 program (Matsumoto et al., 2001). The groundwater level sensitivity at each observation station was determined from these estimated tidal components (Table 1). We used the fault model of Awata et al. (2007) to calculate the coseismic volumetric strain changes caused by the Noto Hanto Earthquake in 2007. The length and width of the fault model are 15 and $12 \mathrm{~km}$, respectively. The upper and western end is situated at 136.61E, 37.23E; the depth of the upper end is $2.0 \mathrm{~km}$, the depth of lower end is $12.4 \mathrm{~km}$, the strike is $58^{\circ}$, the dip is $60^{\circ}$, the rake is $117^{\circ}$, and the slip amount is $1.2 \mathrm{~m}$, which is equal to the earthquake of $M_{\mathrm{w}}$ 6.5. Using this model, we calculated the coseismic volumetric strain change at each station using the program of Okada (1992). The theoretical coseismic groundwater level change was then calculated from the strain sensitivity and

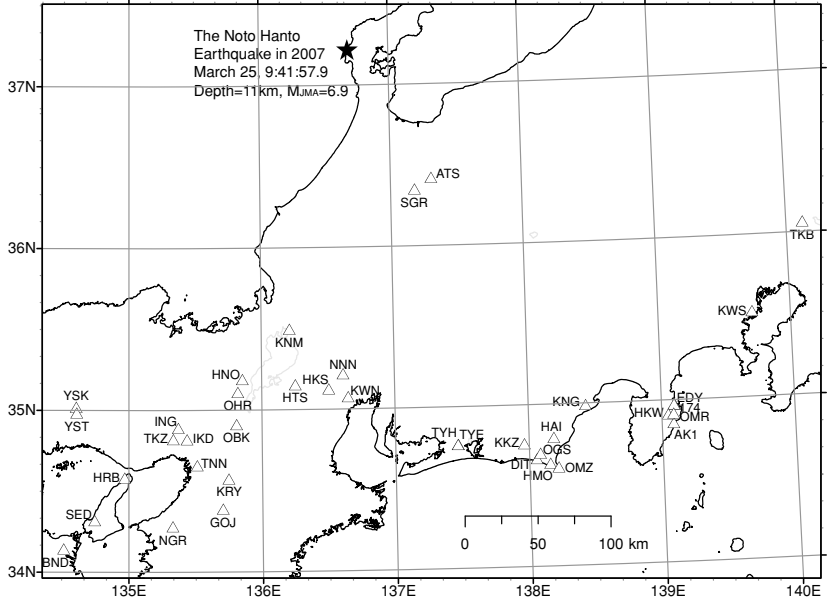

Fig. 1. Location of the groundwater observation stations of Geological Survey of Japan, AIST (triangle mark) and the epicenter of the Noto Hanto Earthquake in 2007 (star mark)

Table 1. Groundwater level sensitivity to volumetric strain and expected groundwater level change from the coseismic volumetric strain change.

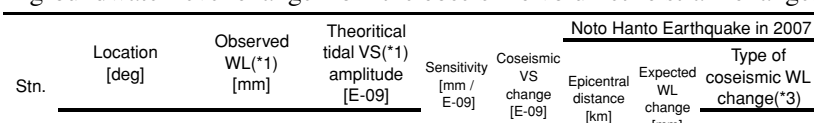

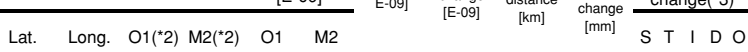
\begin{tabular}{cccccccccccc}
\hline 174 & 34.97 & 139.10 & 30.8 & 58.3 & 2.4 & 6.8 & 8.62 & 1.04 & 331 & -9.0 & $\mathrm{x}$ \\
\hline
\end{tabular} \begin{tabular}{cccccccccccccc}
\hline AK1 & 34.86 & 139.09 & 1.1 & 2.0 & 2.3 & 6.6 & 0.30 & 0.94 & 340 & -0.3 & \\
\hline ATS & 36.42 & 137.31 & 0.2 & 0.3 & 6.7 & 10.0 & 0.03 & 22.04 & 105 & -0.8 & $\times \times$
\end{tabular} \begin{tabular}{cccccccccccc} 
ATS & 36.42 & 137.31 & 0.2 & 0.3 & 6.7 & 10.0 & 0.03 & 22.04 & 105 & -0.8 & $\mathrm{x} \times$ \\
\hline BND & 34.14 & 134.51 & 6.2 & 10.5 & 4.3 & 9.1 & 1.15 & -0.32 & 394 & 0.4 &
\end{tabular} \begin{tabular}{cccccccccccc}
\hline BND & 34.14 & 134.51 & 6.2 & 10.5 & 4.3 & 9.1 & 1.15 & -0.32 & 394 & 0.4 & \\
\hline DIT & 34.67 & 138.06 & 2.7 & 7.9 & 2.2 & 3.1 & 2.52 & 0.82 & 309 & -2.1 & $\mathrm{x}$ \\
\hline
\end{tabular}

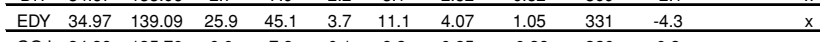

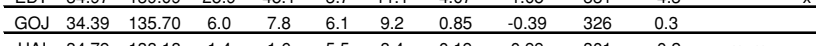
\begin{tabular}{llllllllllll}
\hline HAl & 34.79 & 138.18 & 1.4 & 1.6 & 5.5 & 8.4 & 0.19 & 0.99 & 301 & -0.2 & $\times \quad \times$ \\
\hline
\end{tabular} \begin{tabular}{cccccccccccc}
\hline HKS & 35.13 & 136.50 & 0.2 & 0.1 & 6.5 & 10.3 & 0.01 & -0.38 & 233 & 0.0 & $x$ \\
\hline HKW & 34.91 & 139.05 & 0.0 & 0.0 & 4.5 & 7.6 & 0.00 & 1.01 & 333 & 0.0 &
\end{tabular} \begin{tabular}{lllllllllllll} 
HKW & 34.91 & 139.05 & 0.0 & 0.0 & 4.5 & 7.6 & 0.00 & 1.01 & 333 & 0.0 & & \\
\hline HMO & 34.63 & 138.16 & 0.1 & 0.5 & 1.7 & 6.0 & 0.08 & 0.80 & 316 & -0.1 & $\times$ & $\times \quad \times$ \\
\hline
\end{tabular} \begin{tabular}{lccccccccccccc} 
HMO & 34.63 & 138.16 & 0.1 & 0.5 & 1.7 & 6.0 & 0.08 & 0.80 & 316 & -0.1 & $\mathrm{x}$ & $\mathrm{x}$ & $\mathrm{x}$ \\
\hline HNO & 35.19 & 135.85 & 104.2 & 27.7 & 6.3 & 9.6 & 2.88 & -1.16 & 237 & 3.3 & $\mathrm{x}$ & $\mathrm{x}$ & $\mathrm{x}$ \\
\hline
\end{tabular} \begin{tabular}{llllllllllll}
\hline HRB & 34.58 & 134.97 & 23.4 & 15.6 & 20.7 & 21.1 & 0.74 & -0.52 & 331 & 0.4 & $x$ \\
\hline
\end{tabular} \begin{tabular}{llllllllllllll} 
HTS & 35.15 & 136.25 & 0.0 & 0.0 & 6.3 & 9.6 & 0.00 & -0.77 & 232 & 0.0 & $x$ & $x$ & $x$ \\
\hline
\end{tabular}

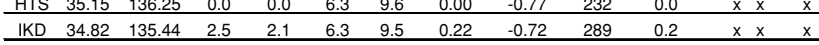

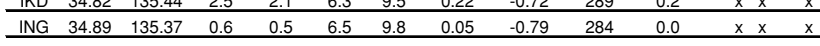
\begin{tabular}{llllllllllllll}
\hline KKZ & 34.76 & 137.96 & 0.0 & 0.1 & 6.1 & 9.5 & 0.01 & 0.90 & 296 & 0.0 & $x$ & $x$ & $x$ \\
\hline
\end{tabular}

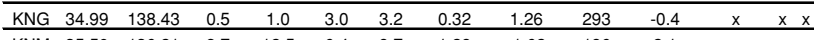

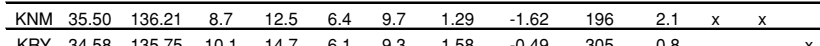
\begin{tabular}{llllllllllll}
\hline KRY & 34.58 & 135.75 & 10.1 & 14.7 & 6.1 & 9.3 & 1.58 & -0.49 & 305 & 0.8 & $x$ \\
\hline KWN & 3508 & 136.65 & 0.8 & 1.6 & 3.3 & 1.9 & 0.87 & -0.13 & 238 & 0.1 & $x$
\end{tabular} \begin{tabular}{lllllllllllll} 
KWN & 35.08 & 136.65 & 0.8 & 1.6 & 3.3 & 1.9 & 0.87 & -0.13 & 238 & 0.1 & & $\mathrm{x}$ \\
\hline KWS & 35.53 & 139.71 & 4.1 & 4.1 & 2.7 & 6.2 & 0.67 & 1.16 & 330 & -0.8 & $\mathrm{x}$ & $\mathrm{x}$ \\
\hline
\end{tabular} \begin{tabular}{ccccccccccccc} 
KWS & 35.53 & 139.71 & 4.1 & 4.1 & 2.7 & 6.2 & 0.67 & 1.16 & 330 & -0.8 & $\mathrm{x}$ & $\mathrm{x}$ \\
\hline $\mathrm{NNN}$ & 35.22 & 136.61 & 16.6 & 55.6 & 6.4 & 10.1 & 5.51 & -0.26 & 222 & 1.4 & & \\
\hline
\end{tabular} \begin{tabular}{cccccccccccc} 
NNN & 35.22 & 136.61 & 16.6 & 55.6 & 6.4 & 10.1 & 5.51 & -0.26 & 222 & 1.4 & \\
\hline OBK & 34.91 & 135.81 & 7.6 & 12.1 & 6.2 & 9.4 & 1.28 & -0.76 & 268 & 1.0 & $x$ \\
\hline
\end{tabular} \begin{tabular}{rrrrrrrrrrrrr} 
OBK & 34.91 & 135.81 & 7.6 & 12.1 & 6.2 & 9.4 & 1.28 & -0.76 & 268 & 1.0 & \\
\hline OGS & 34.70 & 138.08 & 0.3 & 0.2 & 4.1 & 5.2 & 0.04 & 0.86 & 307 & 0.0 & $x$ \\
\hline OHR & 35.11 & 135.82 & 7.8 & 13.9 & 6.3 & 9.6 & 1.46 & -1.03 & 247 & 1.5 & $x$ & $x$ \\
\hline
\end{tabular}

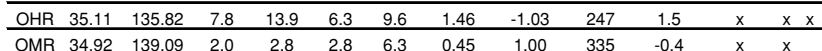

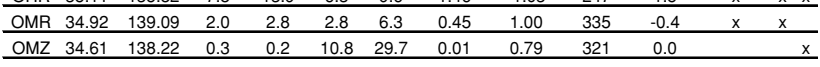

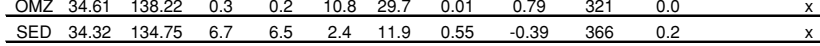
\begin{tabular}{llllllllllll} 
SED & 34.32 & 134.75 & 6.7 & 6.5 & 2.4 & 11.9 & 0.55 & -0.39 & 366 & 0.2 & $\mathrm{x}$ \\
\hline SGR & 36.35 & 137.18 & 5.2 & 2.5 & 6.7 & 10.0 & 0.25 & 15.96 & 106 & -4.0 & \\
\hline
\end{tabular}

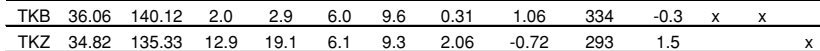
\begin{tabular}{cccccccccccccc}
\hline TKZ & 34.82 & 135.33 & 12.9 & 19.1 & 6.1 & 9.3 & 2.06 & -0.72 & 293 & 1.5 & $x$ \\
\hline TNN & 34.66 & 135.51 & 2.8 & 3.6 & 5.0 & 7.9 & 0.45 & -0.58 & 303 & 0.3 & $x$ \\
\hline
\end{tabular} \begin{tabular}{lllllllllll}
\hline TYE & 34.77 & 137.47 & 0.0 & 0.0 & 5.9 & 8.9 & 0.00 & 0.66 & 281 & 0.0 \\
\hline TYH & 34.77 & 137.47 & 4.4 & 2.9 & 59 & 8.8 & 0.33 & 0.05 & 281 & 0.02
\end{tabular} \begin{tabular}{ccccccccccccc}
\hline TYH & 34.77 & 137.47 & 4.4 & 2.9 & 5.9 & 8.8 & 0.33 & 0.65 & 281 & -0.2 & $\mathrm{x}$ & $\mathrm{x}$ \\
\hline $\mathrm{YSK}$ & 35.02 & 134.60 & 20.8 & 44.8 & 6.6 & 9.6 & 4.66 & -0.67 & 307 & 3.1 & & \\
\hline
\end{tabular}

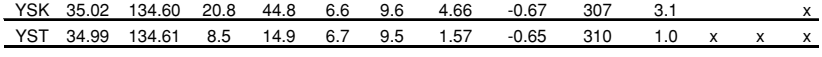
(*1) WL and VS mean water level and volumetric strain, respectively. $(* 2)$ $\mathrm{O} 1$ and M2 denote tidal components. The period of O1 and M2 is 25.8 hours and 12.4 hours, respectively. (*3) S: Step like change, T: Trend change, I: Increase, D: Decrease, O: Oscillation.

coseismic volumetric strain change at each station and compared with the observed change (Table 1).

Similar analyses were carried out for the 2004 Off KiiPeninsula Earthquakes (foreshock and mainshock) (Geographical Survey Institute, 2004; Sato et al., 2005), the 2003 Tokachi-oki Earthquake (Geographical Survey Institute, 2003; Sato et al., 2004), the 2001 Geiyo Earthquake 
(a)
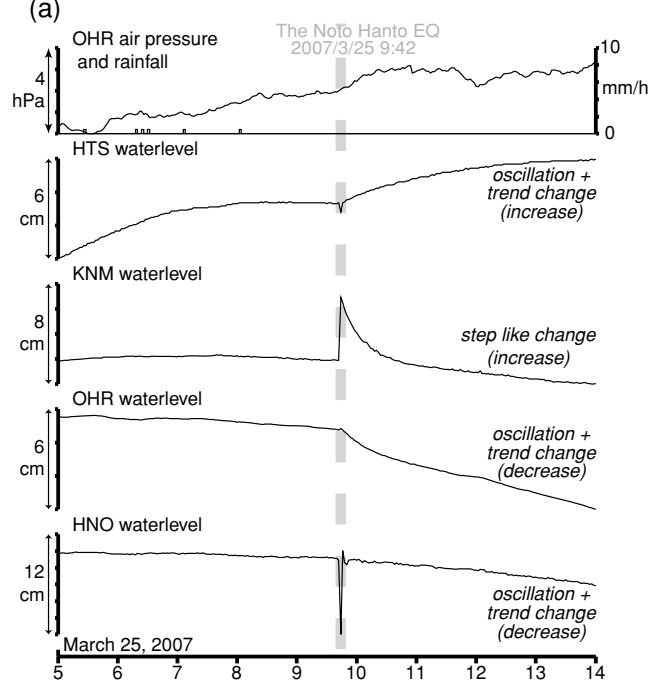

(c)
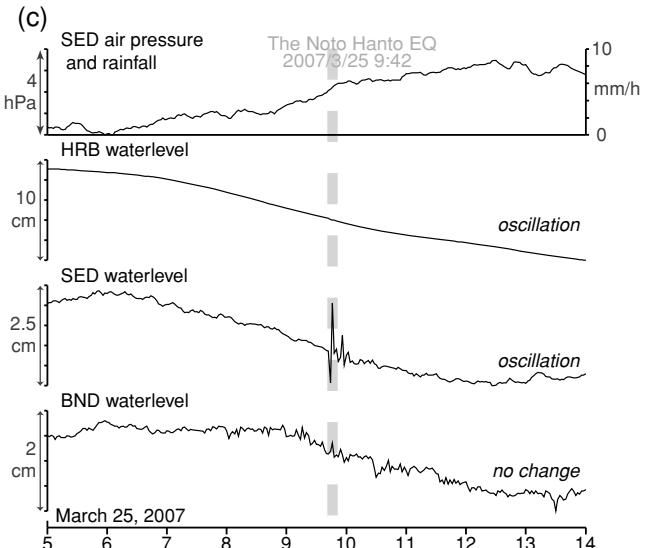

(b)
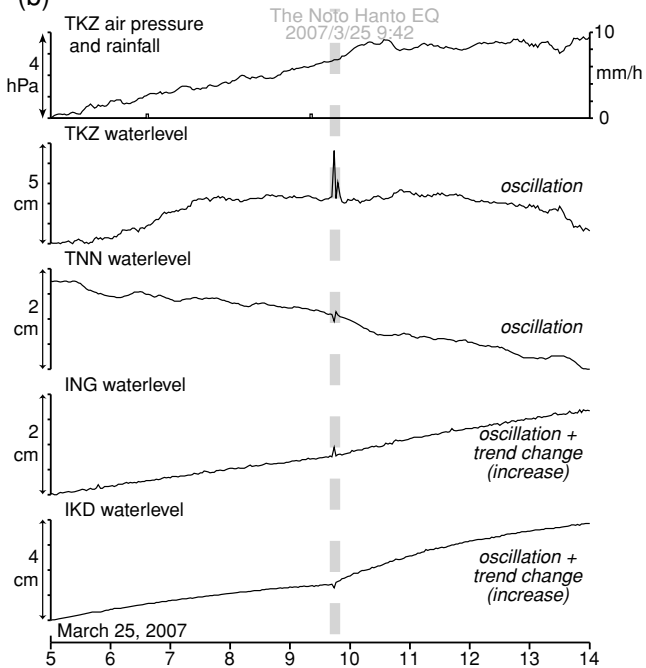

(d)

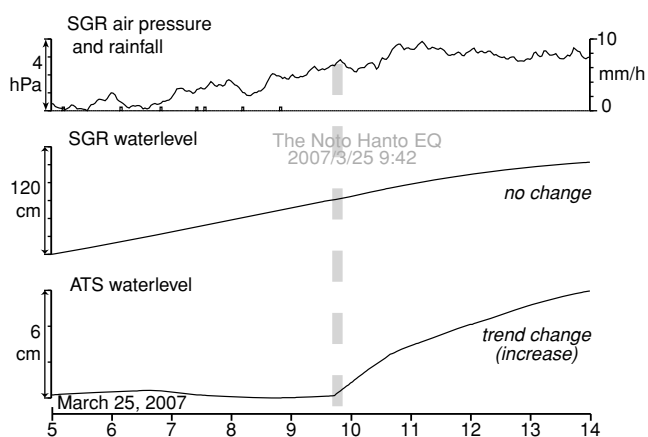

Fig. 2. (a) Observed water level changes at HTS, KNM, OHR and HNO before and after the Noto Hanto Earthquake. The sampling interval is 2 min. (b) Observed water level changes at TKZ, TNN, ING and IKD. (c) Observed water level changes at HRB, SED, and BND. (d) Observed water level changes at SGR and ATS.

(Geographical Survey Institute, 2001; Koizumi et al., 2002) and the Western Tottori Earthquake in 2000 (Geographical Survey Institute, 2000; Takahashi et al., 2002). The results of these analyses were compared with those of the Noto Hanto Earthquake.

\section{Results}

At many of our observation stations, we detected coseismic and/or postseismic groundwater level changes related to the Noto Hanto Earthquake. Most of these were shortterm oscillations and/or changes in the trend. Typical examples of the observed groundwater level changes are shown in Figs. 2(a) to 2(d). Those graphs show 2-min values. Oscillations in the groundwater level occurred at HTS, HNO, TKZ, TNN, ING, IKD and SED. There are several possible factors that could explain why the patterns of the oscillations in the groundwater levels are different: (1) the ground shaking was different at the different stations; (2) aliasing probably occurred because the sampling interval $(2 \mathrm{~min})$ is generally longer than the period of the oscillation; (3) there possibly occurred a kind of resonance so that the oscillation at a certain period, which depends on the geometrical structure of the well, is amplified (Cooper et al., 1965; Kunugi et al., 2000). Resonance is considered to have oc- curred at SED in particular, where the oscillation continued for longer time than at the other stations. At KNM, there was a step-like change in the groundwater level. However, such step-like coseismic changes were observed only at three stations (KNM, TKB, and YST); at the other 13 stations, there were changes in the trend of the groundwater level (Table 1).

It is difficult to evaluate the oscillations of the groundwater level because aliasing probably occurred. The steplike coseismic changes were easy to quantitatively evaluate, but were only observed at the three stations mentioned above. Therefore, we principally evaluated the 13 coseismic changes in the trend of the groundwater level, although quantitative evaluation of the trend changes was usually difficult. Ultimately, we were able to estimate the amount of coseismic water level change only at five stations (KNM, TKB, YST, ATS and HTS).

\section{Discussion}

As mentioned above, we were unable to estimate the amplitudes of the changes in the long-term trend for many stations. However their final amplitudes were at the very least larger than a few millimeters. The coseismic volumetric strain changes were calculated at the observation stations 


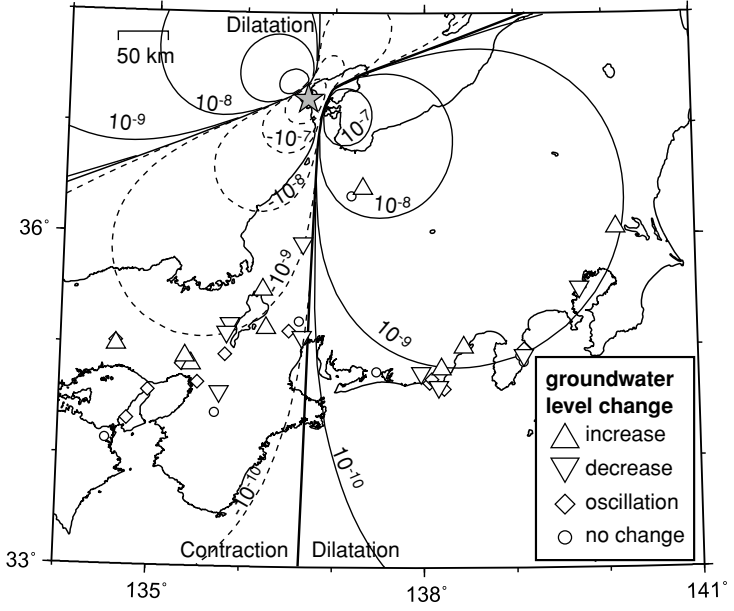

Fig. 3. Coseismic groundwater level changes in response to the Noto Hanto Earthquake in 2007. Contours denote the coseismic volumetric strain changes calculated from the fault model of Awata et al. (2007).

using the fault model of Awata et al. (2007). Most of these changes range between $10^{-9}$ and $10^{-10}$ (Table 1; Fig. 3). Therefore coseismic groundwater level changes expected from those volumetric strain changes are smaller than $1 \mathrm{~mm}$ at most of the stations where the coseismic trend changes were observed (Table 1). This suggests that those trend changes were not caused by the volumetric strain changes but by the ground shaking. According to Montgomery and Manga (2003), ground shaking can cause consolidation, fracturing, and fracture cleaning of the ground. Consolidation seems also to cause permeability to decrease, while fracturing or/and fracture cleaning can cause it to increase. When such permeability changes occur, it is assumed that pressure distribution in the aquifer will shift to a new equilibrium situation. Since the movement of groundwater usually takes much time, the groundwater pressure at a certain point changes gradually, which is considered to be the cause of the many long-term trend changes that were observed.

At the five stations where the amount of coseismic water level changes were estimated, we investigated the relation among the epicentral distances, calculated coseismic volumetric strain changes and coseismic groundwater level changes expected from those volumetric strain changes and observed coseismic water level changes (Fig. 4). Figure 4 shows a kind of linear relation between the epicentral distances and observed water level changes although both the volumetric strain changes and expected groundwater level changes have no relation to observed groundwater level changes. In general, if the coseismic change is caused by the strain change, it decreases in inverse proportion to the cube of the hypocentral distance, which is almost equal to the epicentral distance in the far-field area in the case of a shallow earthquake, such as the Noto Hanto Earthquake in 2007. In contrast, if the coseismic change is caused by ground shaking, it decreases in inverse proportion to the hypocentral distance for the body wave or to the route of the epicentral distance for the surface wave. These results in Fig. 4 also suggest that the water level changes were caused by ground shaking.

In order to clarify the effect of ground shaking on the

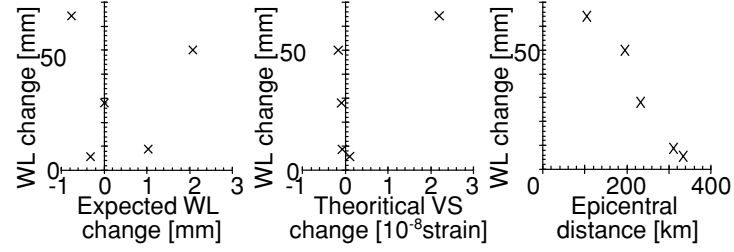

Fig. 4. Relation among the epicentral distances, theoretical volumetric strain changes calculated from the fault model of Awata et al. (2007), coseismic water level changes expected from the volumetric strain changes and observed water level changes at the five stations (ATS, HTS, KNM, TKB and YST) where the amount of coseismic water level change was estimated. *WL and VS mean water level, and volumetric strain change, respectively.

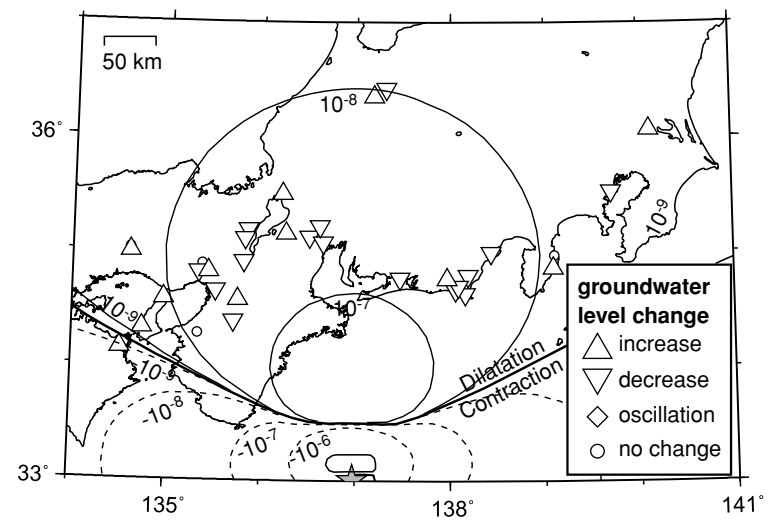

Fig. 5. Coseismic groundwater level change in response to the foreshock of the 2004 Off Kii-Peninsula Earthquakes (Sato et al., 2005). Contours denote the coseismic volumetric strain changes calculated from the fault model of the Geographical Survey Institute (2004).

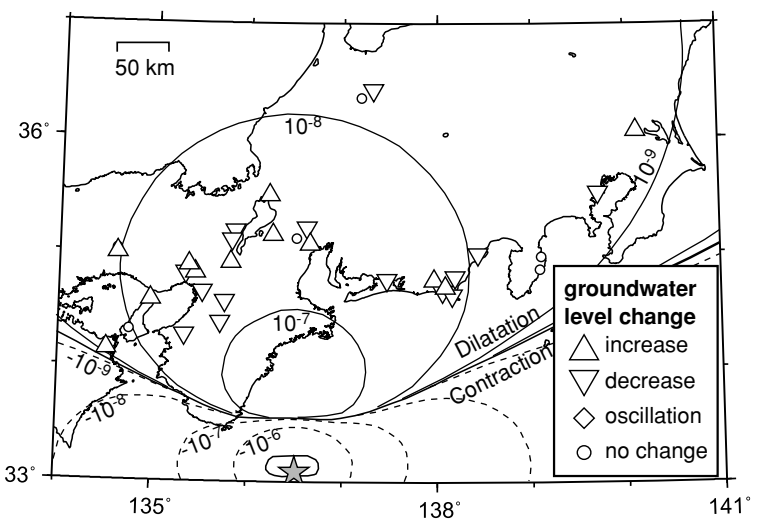

Fig. 6. Coseismic groundwater level changes in response to the mainshock of the 2004 Off Kii-Peninsula Earthquakes (Sato et al., 2005). Contours denote the coseismic volumetric strain changes calculated from the fault model of the Geographical Survey Institute (2004).

groundwater level at each observation station, we compared the coseismic groundwater level changes for Noto Hanto Earthquake with those for the recent large earthquakes. These are shown in Table 2 and in Figs. 5-9. The earthquakes shown are the foreshock and main shock of the 2004 Off Kii-Peninsula Earthquakes (Figs. 5 and 6, respectively), the 2003 Tokachi-Oki Earthquake (Fig. 7), the 2001 Geiyo Earthquake (Fig. 8) and the Western Tottori Earthquake in 2000 (Fig. 9). In the following discussion we did not con- 
Table 2. Observed coseismic groundwater level change and calculated volumetric strain change in response to five recent large earthquakes. For WL, I, D and $\mathrm{O}$, refer to the caption of Table 1 . For a-e in the column of classification, refer to the text.

\begin{tabular}{|c|c|c|c|c|c|c|c|c|c|c|c|c|c|c|c|}
\hline \multirow[b]{2}{*}{ Stn. } & \multicolumn{2}{|c|}{2007 Noto Hanto } & \multicolumn{2}{|c|}{$\begin{array}{c}2004 \text { Off Kii-Pen. } \\
\text { (mainshock) }\end{array}$} & \multicolumn{2}{|c|}{$\begin{array}{c}2004 \text { Off Kii-Pen. } \\
\text { (foreshock) }\end{array}$} & \multicolumn{2}{|c|}{2003 Tokachi-oki } & \multicolumn{2}{|c|}{2001 Geiyo } & \multicolumn{2}{|c|}{$\begin{array}{c}2000 \text { Western } \\
\text { Tottori }\end{array}$} & \multirow{2}{*}{$\begin{array}{l}\text { number of } \\
\text { under } 10^{-8} \\
\text { (VS) }\end{array}$} & \multirow{2}{*}{$\begin{array}{c}\text { number } \\
\text { of I or } \\
D\end{array}$} & \multirow{2}{*}{$\begin{array}{l}\text { classifi- } \\
\text { cation }\end{array}$} \\
\hline & $\begin{array}{l}\text { Type of } \\
\text { WL } \\
\text { change }\end{array}$ & $\begin{array}{l}\text { Strain } \\
\text { change } \\
{[\mathrm{E}-09]}\end{array}$ & $\begin{array}{l}\text { Type of } \\
\text { WL } \\
\text { change }\end{array}$ & $\begin{array}{c}\text { Strain } \\
\text { change } \\
{[\mathrm{E}-09]}\end{array}$ & $\begin{array}{c}\text { Type of } \\
\text { WL } \\
\text { change }\end{array}$ & $\begin{array}{c}\text { Strain } \\
\text { change } \\
{[\mathrm{E}-09]}\end{array}$ & $\begin{array}{c}\text { Type of } \\
\text { WL } \\
\text { change }\end{array}$ & $\begin{array}{c}\text { Strain } \\
\text { change } \\
{[\mathrm{E}-09]}\end{array}$ & $\begin{array}{c}\text { Type of } \\
\text { WL } \\
\text { change }\end{array}$ & $\begin{array}{l}\text { Strain } \\
\text { change } \\
{[\mathrm{E}-09]}\end{array}$ & $\begin{array}{c}\text { Type of } \\
\text { WL } \\
\text { change }\end{array}$ & $\begin{array}{l}\text { Strain } \\
\text { change } \\
{[\mathrm{E}-09]}\end{array}$ & & & \\
\hline 174 & 0 & 1.04 & $\mathrm{~N}$ & 8.08 & $\mathrm{~N}$ & 3.29 & 0 & -1.85 & & & $\mathrm{~N}$ & 0.42 & 5 & 0 & $\mathrm{e}$ \\
\hline AK1 & $N(* 1)$ & 0.94 & 1 & 8.01 & $\mathrm{~N}$ & 3.03 & - & & - & - & $\mathrm{N}$ & 0.44 & 4 & 1 & $\mathrm{e}$ \\
\hline ATS & $\frac{1+2)}{1+2)}$ & 22.03 & $\mathrm{D}$ & 9.91 & $D$ & 7.43 & $\mathrm{~N}$ & -2.22 & - & - & $\mathrm{N}$ & 0.30 & 4 & 2 & $a$ \\
\hline BND & $\mathrm{N}$ & -0.32 & 1 & -1.30 & 1 & 1.61 & 0 & -0.78 & 1 & -5.93 & 0 & 7.08 & 6 & 3 & $a$ \\
\hline DIT & 0 & 0.82 & $D$ & 40.86 & $D$ & 16.22 & $\mathrm{~N}$ & -1.56 & & & 0 & 0.82 & 3 & 0 & $e$ \\
\hline EDY & 0 & 1.05 & $-(* 3)$ & - & - & - & - & - & - & - & - & - & 1 & 0 & $e$ \\
\hline GOJ & $\mathrm{N}$ & -0.39 & $D$ & 35.78 & $D$ & 65.00 & $\mathrm{~N}$ & -1.04 & 0 & -2.12 & $D$ & 5.26 & 4 & 1 & $\mathrm{e}$ \\
\hline HAl & 1 & 0.98 & $D$ & 30.86 & $D$ & 12.95 & $\mathrm{~N}$ & -1.65 & - & - & $\mathrm{D}$ & 0.75 & 3 & 2 & $d$ \\
\hline HKS & 0 & -0.38 & $D$ & 40.32 & $N$ & 35.88 & $\mathrm{~N}$ & -1.40 & 0 & -1.08 & D & 2.58 & 4 & 1 & $\mathrm{e}$ \\
\hline$H K W$ & $N$ & 1.01 & & & & & $\mathrm{~N}$ & -1.80 & - & - & $N$ & 0.44 & 3 & 0 & $e$ \\
\hline $\mathrm{HMO}$ & D & 0.80 & $D$ & 36.23 & $D$ & 13.70 & $\mathrm{~N}$ & -1.56 & - & - & 0 & 0.77 & 3 & 1 & $\mathrm{e}$ \\
\hline HNO & $\mathrm{D}$ & -1.16 & $D$ & 24.30 & $D$ & 27.26 & 0 & -1.23 & 0 & -1.65 & $\mathrm{D}$ & 5.06 & 4 & 2 & $a$ \\
\hline HRB & 0 & -0.52 & 1 & 8.63 & 1 & 16.70 & $\mathrm{~N}$ & -0.92 & D & -4.11 & $D$ & 14.57 & 4 & 2 & $\frac{u}{d}$ \\
\hline HTS & 1 & -0.77 & 1 & 34.01 & 1 & 33.43 & $\mathrm{~N}$ & -1.34 & 1 & -1.27 & 1 & 3.28 & 4 & 3 & $a$ \\
\hline $\mathrm{IKD}$ & 1 & -0.72 & 1 & 19.81 & 1 & 29,14 & $\mathrm{~N}$ & -1.05 & 1 & -2.57 & 1 & 9.23 & 4 & 3 & $a$ \\
\hline ING & 1 & -0.79 & $N$ & 17.59 & 1 & 25.37 & $\mathrm{~N}$ & -1.05 & 1 & -2.65 & $I$ & 10.28 & 3 & 2 & $a$ \\
\hline KKZ & $\mathrm{D}$ & 0.90 & 1 & 42.01 & 1 & 18.22 & & & - & & 1 & 0.86 & 2 & 2 & $d$ \\
\hline KNG & D & 1.26 & $D$ & 19.80 & D & 8.86 & $\mathrm{D}$ & -1.80 & - & - & $D$ & 0.62 & 4 & 4 & $a$ \\
\hline KNM & 1 & -1.62 & 1 & 22.35 & 1 & 21.24 & 1 & -1.41 & 1 & -1.15 & 1 & 2.67 & 4 & 4 & $a$ \\
\hline KRY & 0 & -0.49 & 1 & 35.95 & $D$ & 55.00 & - & & 1 & -2.05 & $\mathrm{D}$ & 5.67 & 3 & 2 & $\mathrm{c}$ \\
\hline KWN & 0 & -0.13 & $D$ & 45.68 & 1 & 38.19 & 1 & -1.43 & 0 & -0.99 & 1 & 2.29 & 4 & 2 & $a$ \\
\hline KWS & D & 1.16 & $D$ & 3.93 & D & 1.93 & D & -2.34 & - & .ivo & $\mathrm{N}$ & 0.27 & 5 & 4 & $a$ \\
\hline NGR & & & $N$ & 14.05 & $D$ & 34.18 & $\mathrm{~N}$ & -0.95 & 0 & -2.91 & $D$ & 6.72 & 4 & 1 & $\mathrm{e}$ \\
\hline NNN & $\mathrm{N}$ & -0.26 & $D$ & 36.99 & $D$ & 31.33 & $\mathrm{~N}$ & -1.46 & 0 & -0.98 & $D$ & 2.23 & 4 & 1 & $e$ \\
\hline OBK & 0 & -0.76 & $D$ & 30.10 & ()$\left.^{*} 4\right)$ & 37.60 & 1 & -1.16 & 1 & -1.86 & D & 5.77 & 4 & 3 & ()$\left.^{*} 5\right)$ \\
\hline OGS & 0 & 0.86 & $D$ & 38.29 & $\frac{17}{1}$ & 15.45 & $\mathrm{~N}$ & -1.58 & - & - & D & 0.80 & 3 & 1 & $\mathrm{e}$ \\
\hline $\mathrm{OHR}$ & $D$ & -1.03 & $D$ & 25.38 & $D$ & 29.45 & D & -1.20 & $D$ & -1.74 & D & 5.47 & 4 & 4 & $a$ \\
\hline OMR & $D$ & 1.00 & & & & & $\mathrm{~N}$ & -1.81 & - & & $\mathrm{N}$ & 0.43 & 3 & 1 & $e$ \\
\hline OMZ & 0 & 0.79 & - & & - & & $\mathrm{N}$ & -1.55 & - & - & 0 & 0.74 & 3 & 0 & $\mathrm{e}$ \\
\hline SED & 0 & $\begin{array}{l}-0.39 \\
\end{array}$ & $I$ & 2.60 & $\mathrm{~N}$ & 8.62 & $\mathrm{~N}$ & -0.84 & 1 & -5.11 & $D$ & 11.36 & 5 & 2 & $a$ \\
\hline SGR & $N$ & 15.96 & 1 & 10.69 & $\mathrm{~N}$ & 8.14 & $\mathrm{~N}$ & -2.11 & - & & $\mathrm{N}$ & 0.36 & 3 & 0 & $e$ \\
\hline TKB & I & 1.06 & 1 & 2.62 & $\left({ }^{*} 4\right)$ & 1.44 & 1 & -3.00 & - & - & $\mathrm{N}$ & 0.17 & 5 & 4 & $\left({ }^{*} 6\right)$ \\
\hline TKZ & 0 & -0.72 & $D$ & 17.05 & $D$ & 25,75 & 0 & -1.03 & $\perp$ & -2.80 & $D$ & 10.65 & 3 & 1 & $e$ \\
\hline TNN & 0 & -0.58 & $D$ & 23.58 & $D$ & 37.30 & 1 & -1.05 & D & -2.49 & D & 7.80 & 4 & 3 & $d$ \\
\hline TYE & $\mathrm{N}$ & 0.66 & - & & - & - & - & - & - & - & - & - & 1 & 0 & $\mathrm{e}$ \\
\hline TYH & $\mathrm{D}$ & 0.65 & $D$ & 66.85 & $D$ & 34.88 & $\mathrm{~N}$ & -1.51 & - & & $\mathrm{D}$ & 1.22 & 3 & 2 & $b$ \\
\hline YSK & 0 & -0.67 & $\mathrm{~N}$ & 5.89 & $\mathrm{~N}$ & 9.13 & 0 & -0.88 & 1 & -4.50 & 0 & 42.18 & 5 & 1 & $\mathrm{e}$ \\
\hline YST & 1 & -0.65 & 1 & 5.85 & 1 & 9.23 & 0 & $\begin{array}{l}-0.87 \\
\end{array}$ & & & $D$ & 41.15 & 4 & 3 & $a$ \\
\hline
\end{tabular}

$(* 1) \mathrm{N}$ means no detection of the coseismic groundwater level change. $(* 2)$ Characters or numbers in bold italics show that coseismic volumetric strain change is $10^{-8}$ or greater. $(* 3)$ "“- means there was no observed data. $(* 4)$ The results at two wells at the same observation station were different. $(* 5)$ $\mathrm{c}$ at OBK1, d at OBK2. $(* 6)$ a at TKB3, d at TKB4.

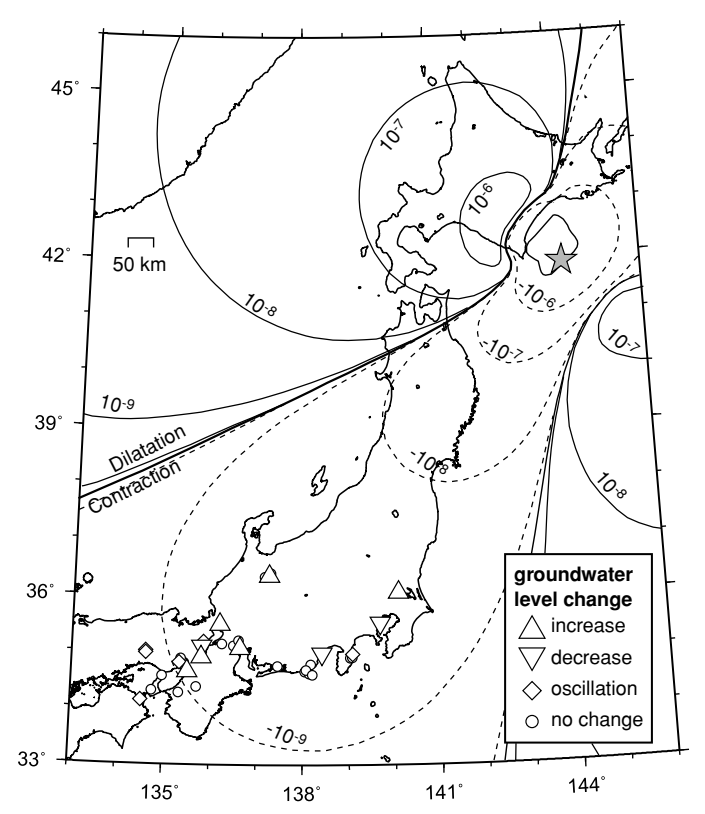

Fig. 7. Coseismic groundwater level changes in response to the 2003 Tokachi-Oki Earthquake (Akita and Matsumoto, 2004; Sato et al., 2004). Contours denote the coseismic volumetric strain changes calculated from the fault model of the Geographical Survey Institute (2003).

sider the results at the groundwater stations where there were no or only one coseismic change related to those earthquakes. We also focused our attention on those groundwater level changes at the observation stations where estimated coseismic volumetric strain changes were smaller

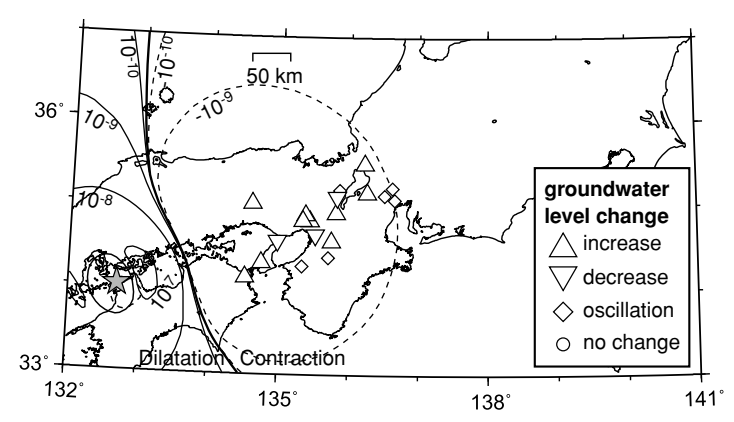

Fig. 8. Coseismic groundwater level changes in response to the 2001 Geiyo Earthquake (Koizumi et al., 2002). Contours denote the coseismic volumetric strain changes calculated from the fault model of the Geographical Survey Institute (2001).

than $10^{-8}$. We found five groups of observation stations:

(a) ones in which the direction (rise or drop) of the water level changes was constant and inconsistent with that of the coseismic volumetric strain changes at the station;

(b) ones in which the direction of the water level changes was constant and consistent with that of coseismic volumetric strain changes;

(c) ones in which the direction of the water level changes was variable and consistent with that of the coseismic volumetric strain changes;

(d) ones in which the direction of the water level changes was variable and inconsistent with that of the coseismic volumetric strain changes; 


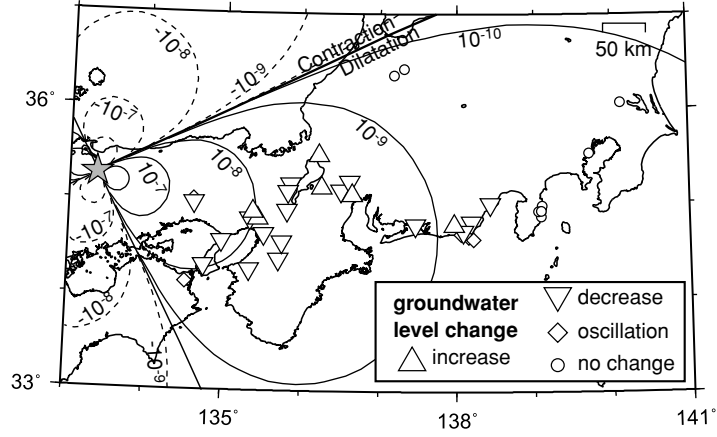

Fig. 9. Coseismic groundwater level changes in response to the Western Tottori Earthquake in 2000 (Takahashi et al., 2002). Contours denote the coseismic volumetric strain changes calculated from the fault model of the Geographical Survey Institute (2000).

Table 3. Classification of the stations based on the pattern of the coseismic changes.

\begin{tabular}{cccccccc}
\hline Class & Num. & \multicolumn{7}{c}{ Station } \\
\hline \multicolumn{1}{c}{ a } & 14 & ATS & BND & HNO & HTS & IKD & ING \\
& & KST & TKB & KWN & KWS & OHR & SED \\
\hline$b$ & 1 & TYH & & & & & \\
\hline$c$ & 2 & KRY & OBK1 & & & & \\
\hline$d$ & 6 & HAl & HRB & KKZ & OBK2 & TNN & TKB4 \\
\hline & & 174 & AK1 & DIT & EDY & GOJ & HKS \\
e & 17 & HKW & HMO & NGR & NNN & OGS & OMR \\
& & OMZ & SGR & TKZ & TYE & YSK & \\
\hline
\end{tabular}

(e) the other stations, which include those stations where there was no or only one coseismic groundwater level change (Tables 2 and 3).

We consider that consolidation, fracturing, fracture clearing or liquefaction could easily have been caused by ground shaking at stations belonging to categories (a) and (d). Those stations that belong to category (c) might be sensitive to the coseismic volumetric strain changes. However there are few of such stations. Based on our results, we are unable to make an assessment of the stations belonging to groups (b) and (e) (Table 3).

We have determined the rough characteristics of the effect of ground shaking on the groundwater level. In order to obtain more details on these characteristics and to clarify the mechanisms which produce the effect at each of the stations, we need the observation records of coseismic groundwater levels whose sampling interval is much shorter than $2 \mathrm{~min}$. The effect of ground shaking is conspicuous in the groundwater oscillation and because of this, an understanding of groundwater oscillations is important to our understanding of the mechanism of earthquake-related groundwater changes. We are now ready for a high-sampling groundwater level observation system.

\section{Conclusions}

There were many coseismic and/or postseismic groundwater level changes related to the Noto Hanto Earthquake in 2007 at the groundwater observation stations of the Geological Survey of Japan, AIST. At the five stations where the amount of coseismic water level change was estimated in this study, a kind of linear relation is recognized between the epicentral distance and the observed coseismic water level change for the Noto Hanto Earthquake in 2007. The estimated coseismic volumetric strain changes are smaller than $10^{-8}$ at most of the observation stations. Therefore, it is considered that most of observed groundwater level changes in the Noto Hanto Earthquake in 2007 were caused by ground shaking. We compared the coseismic groundwater level changes for Noto Hanto Earthquake with those for five recent large earthquakes and determined the rough characteristics of the effect of the ground shaking on the groundwater level at each of the observation stations.

Acknowledgments. We thank Dr. Tsukuda and an anonymous reviewer for valuable comments to improve this paper. We are grateful to the many people who have helped us with our groundwater observations.

\section{References}

Akita, F. and N. Matsumoto, Hydrological responses induced by the Tokachi-oki Earthquake in 2003 at hot spring wells in Hokkaido, Japan, Geophys. Res. Lett., 31, L16603, 2004.

Awata, Y., S. Toda, T. Azuma, H. Kaneda, and H. Horikawa, Preliminary results of research of the Noto Hanto earthquake in 2007 (Geography and Geology), http://unit.aist.go.jp/actfault/katsudo/jishin/ notohanto/report/070403.html, 2007 (in Japanese).

Brodsky, E., E. Roeloffs, D. Woodcock, I. Gall, and M. Manga, A mechanism for sustained groundwater pressure changes induced by distant earthquakes, J. Geophys. Res., 108(B8), 2390, 2003.

Cooper, H. H., Jr., D. Bredehoeft, I. S. Paradopulos, and R. R. Bennet, The response of well-aquifer systems to seismic waves, J. Geophys. Res., 70 , 3915-3926, 1965.

Geographical Survey Institute, http://www.gsi.go.jp/WNEW/PRESSRELEASE/2000/1007-2.htm, 2000 (in Japanese).

Geographical Survey Institute, Crustal Movements in the Chugoku, Shikoku and Kyushu Districts, Report of The Coordinating Committee for Earthquake Prediction, 66, 486-512, 2001 (in Japanese).

Geographical Survey Institute, http://www.gsi.go.jp/WNEW/PRESSRELEASE/2003/0926-2.htm, 2003 (in Japanese).

Geographical Survey Institute, http://www.gsi.go.jp/WNEW/PRESSRELEASE/2004/0906.htm, 2004 (in Japanese).

Igarashi, G. and H. Wakita, Tidal responses and earthquake-related changes in the water level of deep wells, J. Geophys. Res., 96, 42694278, 1991.

Kitagawa, Y., N. Koizumi, M. Takahashi, N. Matsumoto, T. Sato, Y. Kuwahara, H. Ito, A. Cho, T. Satoh, and E. Tsukuda, Estimation of barometric responses of groundwater levels at observation stations of the Geological Survey of Japan, AIST in and around Kinki district, Bull. Geol. Surv. Jpn., 55, 129-152, 2004 (in Japanese with English abstract).

Koizumi, N., Y. Kano, Y. Kitagawa, T. Sato, M. Takahashi, S. Nishimura, and R. Nishida, Groundwater anomalies associated with the Hyogo-ken Nanbu Earthquake 1995, J. Phys. Earth, 44, 373-380, 1996.

Koizumi, N., Y. Kitagawa, M. Takahashi, T. Sato, N. Matsumoto, H. Ito, Y. Kuwahara, A. Cho, and T. Satoh, Changes in groundwater level and crustal strain in and around the Kinki District related to the 2001 Geiyo Earthquake, Zisin, 55, 119-127, 2002 (in Japanese with English abstract).

Koizumi, N., Y. Kitagawa, N. Matsumoto, M. Takahashi, T. Sato, O. Kamigaichi, and K. Nakamura, Pre-seismic groundwater level changes induced by crustal deformations related to earthquake swarms off the east coast of Izu Peninsula, Japan, Geophys. Res. Lett., 31, L10606, doi: 10.1029/2004GL019557, 2004.

Kunugi, T., Y. Fukao, and M. Ohno, Underdamped responses of a well to nearby swarm earthquakes off the coast of Ito City, central Japan, 1995, J. Geophys. Res., 105(B4), 7805-7818, 2000.

Lai, W.-C., N. Koizumi, N. Matsumoto, Y. Kitagawa, C.-W. Lin, C.-L. Shieh, and Y.-P. Lee, The effect of the seismic ground motion and geological setting on the coseismic groundwater level changes caused by the 1999 Chi-Chi Earthquake, Taiwan, Earth Planets Space, 56, 873880, 2004.

Matsumoto, K., T. Sato, T. Takanezawa, and M. Ooe, GOTIC2: A Program for Computation of Oceanic Tidal Loading Effect, J. Geod. Soc. Jpn., 47, 243-248, 2001.

Montgomery, D. R. and M. Manga, Streamflow and Water Well Responses 
to Earthquakes, Science, 300, 2047-2049, 2003.

Okada, Y., Internal deformation due to shear and tensile faults in a halfspace, Bull. Seismol. Soc. Am., 82, 1018-1040, 1992.

Quilty, E. G. and E. A. Roeloffs, Water level changes in response to the December 20, 1994 M4.7 earthquake near Parkfield, California, Bull. Seismol. Soc. Am., 87, 310-317, 1997.

Roeloffs, E. A., Hydrologic precursors to earthquakes, A preview, Pure Appl. Geophys., 126, 177-209, 1988.

Roeloffs, E., Poroelastic techniques in the study of earthquake-related hydrologic phenomena, in Advances in Geophysics, edited by $\mathrm{R}$. Dmowska, 135-195, Academic Press, San Diego, 1996.

Rojstaczer, S., S. Wolf, and R. Michel, Permeability enhancement in the shallow crust as a cause of earthquake-induced hydrological changes, Nature, 373, 237-239, 1995.

Sato, T., N. Matsumoto, Y. Kitagawa, N. Koizumi, M. Takahashi, Y. Kuwahara, H. Ito, A. Cho, T. Satoh, K. Ozawa, and S. Tasaka, Changes in groundwater level associated with the 2003 Tokachi-oki earthquake, Earth Planets Space, 56, 395-400, 2004.
Sato, T., N. Matsumoto, Y. Kitagawa, N. Koizumi, M. Takahashi, Y. Kuwahara, A. Cho, T. Satoh, and K. Ozawa, Report of changes in groundwater levels associated with the 2004 Off Kii-Peninsula earthquakes, Chishitsu News, 611, 60-71, 2005 (in Japanese).

Takahashi, M., N. Koizumi, T. Sato, N. Matsumoto, H. Ito, Y. Kuwahara, A. Cho, and T. Satoh, Changes in groundwater level and crustal strain in and around the Kinki District related to the Western Tottori Earthquake in 2000, Zisin, 55, 75-82, 2002 (in Japanese with English abstract).

Tamura, Y., T. Sato, M. Ooe, and M. Ishiguro, A procedure for tidal analysis with a Bayesian information criterion, Geophys. J. Int., 104, 507-516, 1991.

Wakita, H., Water wells as possible indicators of tectonic strain, Science, 189, 553-555, 1975.

S. Itaba (e-mail: itaba-s@aist.go.jp), N. Koizumi, N. Matsumoto, M. Takahashi, T. Sato, R. Ohtani, Y. Kitagawa, Y. Kuwahara, T. Sato, and K. Ozawa 